\section{Somatic Embryogenesis and Regeneration from Cotyledon Explants of Six Squash Cultivars}

\author{
Carol Gonsalves, Baodi Xue ${ }^{1}$, and Dennis Gonsalves \\ Department of Plant Pathology, Cornell University, New York State Agricultural \\ Experiment Station, Geneva, NY 14456
}

Additional index words. Cucurbita pepo, plant tissue culture

\begin{abstract}
Six summer squash (Cucurbita pepo L.) cultivars were regenerated via somatic embryogenesis using cotyledons excised from germinated or nongerminated seeds. Genotypes included were zucchini, commercial $F_{1}$ hybrids, 'President', 'Seneca Zucchini', 'Jade'; the noncommercial inbred line 'Caserta Inbred 557311'; and two yellow squash hybrids 'Dixie' and 'Seneca Butterbar'. Somatic embryogenesis was initiated in induction medium containing $22.62 \mu_{\mathrm{M}} 2,4-\mathrm{D}$, and embryos were germinated in maturation medium containing $0.27 \mu_{\mathrm{M}} \mathrm{NAA}$ and $0.23 \mu_{\mathrm{M}}$ kinetin. Plants were elongated and rooted on basal

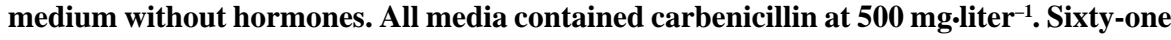
percent of the 'Seneca Butterbar' cotyledons produced somatic embryos when kept on induction medium for 10 weeks. Overall, $7 \%$ of the initial explants produced plantlets, and regeneration efficiency was calculated as 0.3 plantlets per initial explant. The relative production of plants from cotyledons that were kept on induction medium for different time periods were determined for 'Caserta Inbred 557311' and 'Seneca Zucchini'. All cotyledons produced somatic embryos after 11 to 17 weeks on induction medium. However, plantlet production was optimal with explants kept on induction medium for 13 weeks for 'Seneca Zucchini' and for 15 weeks for 'Caserta Inbred 557311', producing an average of 4.5 and 9.3 plants per explant, respectively, from $90 \%$ to $70 \%$ of the explants. We recovered plants from all six cultivars; thus, our regeneration protocol may be applicable to other genotypes. The high percentage of regenerants obtained indicates that the regeneration method is efficient enough to be adapted successfully to squash transformation experiments. Chemical names used: $\alpha$-carboxybenzylpenicillin (carbenicillin); 2,4-dichlorophenoxyacetic acid (2,4-D); 6-furfurylaminopurine (kinetin); $\alpha$ napthaleneacetic acid (NAA).
\end{abstract}

Squash production is economically important worldwide; 7.5 million metric tons of squash, pumpkins, and gourds were produced in 1992. These crops provide nourishment for many people, especially those in developing nations where $\approx 80 \%$ of the world's squash, pumpkins, and gourds are produced (Food and Agriculture Organization of the United Nations, 1993). Unfortunately, the cultivated squash has no resistance to diseases caused by destructive viruses such as cucumber mosaic, papaya ringspot, squash mosaic, watermelon mosaic II, and zucchini yellow mosaic. Classical breeding for viral resistance has been performed for years, but to our knowledge, commercially resistant cultivars have not been reported (Munger, 1993).

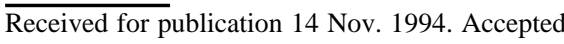
for publication 10 May 1995. We thank P. Chee for answering questions on squash regeneration, $F$. Klas for providing the statistical analysis, $R$. Provvidenti and R.W. Robinson for information on squash culture, N. Lu and S. Ecker-Day for technical assistance, and M. Yepes for help in editing this manuscript. The cost of publishing this paper was defrayed in part by the payment of page charges. Under postal regulations, this paper therefore must be hereby marked advertisement solely to indicate this fact.

${ }^{1}$ Permanent address: Dept. of Plant Protection, Nanjing Agricultural Univ., Nanjing 210014, People's Republic of China.
Promising new technology based on the concept of pathogen-derived resistance (Sanford and Johnston, 1985) has enabled researchers to produce transgenic plants that show resistance to plant viruses. In particular, coat protein-mediated protection (CPMP) has been used successfully to produce plants that are resistant to several viruses (e.g., Beachy et al., 1990). CPMP in transgenic plants is obtained by stably transferring the coat protein gene of the infectious virus into the plant genome either by Agrobacterium tumefaciens or biolistic transformation (e.g., Fitch et al., 1992; Gonsalves et al., 1994). Plants regenerated from transformed cells subsequently are screened to identify those that are resistant to the infectious virus. Moreover, as in classical breeding, this resistance is a heritable trait.

Successful genetic engineering of squash requires a reliable and efficient regeneration system, especially one that can be used with many cultivars. Although Schroder (1968) obtained somatic embryogenesis from squash pericarp tissue, most previous studies involved pumpkins. Plantlets were recovered from embryogenic pumpkin calli using hypocotyls and cotyledons (Jelaska, 1972). More recently, successful squash regeneration was reported for the summer squash 'YC 60', where embryogenic calli induced from shoot apices or from cotyledons of nongerminated seeds (Chee 1991, 1992) developed into plants that pro- duced fruit in the greenhouse. In this study, we report the regeneration of plantlets from embryogenic cotyledons of six additional squash cultivars using a modification of the media and methods used by Chee (1991, 1992).

\section{Materials and Methods}

Mature seeds of the squash cultivars Jade (Ferry-Morse Seed Co., Modesto, Calif.), President (Petoseed Co., Saticoy, Calif.), Dixie (Asgrow Seed Co., Kalamazoo, Mich.) and cultivars Seneca Butterbar, Seneca Zucchini, and Caserta Inbred 557311 (Robson Seed Farms Corp., Hall, N.Y.) were obtained at the New York State Agricultural Expt. Station, Cornell Univ., Geneva. Seeds were soaked in $25 \%$ Clorox for $10 \mathrm{~min}$ and rinsed three times in sterile distilled water before removing the seedcoat. Then the seeds were soaked in $25 \%$ Clorox for $25 \mathrm{~min}$, followed by three rinses in sterile distilled water.

Nongerminated or germinated seeds were used to obtain cotyledon explants. Mature nongerminated seeds were prepared by removing the radicle and the distal one-third of each cotyledon. The resulting explant, with the embryo intact and the cotyledons still joined, was cut longitudinally into four pieces for 'Caserta Inbred 557311' and 'Seneca Butterbar' or two pieces for 'Dixie' and 'Jade'. Explants consisting of a pair of joined cotyledons were embedded into induction medium with the cut, longitudinal edges facing up. For 'President', cotyledons were separated and the distal one-third and the radicle of each were removed, resulting in two explants, one of which contained the cotyledon and the embryo and the other with the cotyledon alone. Adaxial surfaces were embedded into the medium. About 200 cotyledon pieces were cultured per cultivar.

'Seneca Zucchini' seeds were surfacesterilized, then germinated in petri plates containing $15 \mathrm{ml}$ water. Explants were incubated 3 to 4 days at $22 \mathrm{C}$ in darkness. The apical thirds of cotyledons were cut away and discarded. Cotyledons then were trimmed along all other edges without preserving the axis. A longitudinal cut was made through the pair of cotyledons, producing four individual explants from one seed. Initially, these explants were oriented with the adaxial surface pressed into the medium, but they were randomly oriented at later transfers. Two hundred cotyledon pieces were cultured for this cultivar.

Induction medium was basal MS medium (Murashige and Skoog, 1962) with $22.62 \mu_{\mathrm{M}}$ 2,4-D (Chee, 1992). Initially, explants were maintained on embryo induction medium for 10 weeks, as reported by Chee (1991). However, we also conducted experiments to optimize the embryo induction period. For 'Seneca Zucchini' and 'Caserta Inbred 557311', explants were randomly separated into groups and maintained on embryo induction medium for 11 to 19 weeks; then the percentage of explants that developed plantlets was determined. For maturation of embryos, we used MS medium containing $0.27 \mu \mathrm{M}$ NAA and $0.23 \mu \mathrm{m}$ kinetin (Chee, 1991) for 4 to 8 weeks. 
For elongation and further root development, embryos were kept in MS-based medium without hormones for $\approx 3$ weeks. All media contained $3 \%$ sucrose and $0.8 \%$ agar adjusted to $\mathrm{pH} 5.8$ and were autoclaved $20 \mathrm{~min}$ at $121 \mathrm{C}$. Filter-sterilized carbenicillin at $500 \mathrm{mg}$ liter $^{-1}$ was added to all media. A total of $50 \mathrm{ml}$ of medium was dispensed into $100 \times 25-\mathrm{mm}$ petri plates (embryo induction and maturation) and into Magenta boxes (elongation and further root development). Explants (8 to 10 per plate) were initially incubated at $22 \mathrm{C}$ in darkness during somatic embryo formation and then moved to light at $25 \mathrm{C}$ with a daily $16-$ $\mathrm{h}$ photoperiod $\left(76 \mu \mathrm{mol} \cdot \mathrm{m}^{-2} \cdot \mathrm{s}^{-1}\right)$ for maturation and further development of somatic embryos.

A probit analysis computer program written by Tang Zhung Ming (Academy of Chinese Military Medical Sciences, Institute of Radiation Medicine, Dept. of Pharmacology, Beijing, People's Republic of China) was used to determine $95 \%$ confidence intervals for the optimal time that explants were kept on induction medium. The number of days the explants were exposed to the embryo induction medium was considered the dose and the numbers of plantlets produced during the consecutive exposure times (11 to 19 weeks) as the response. The response was converted into probits, on the basis of which the probit analysis was executed. The number of days on induction medium needed for explants to yield $50 \%$ of the total number of plantlets (ND-50) was used as a measure to find the optimal time for explants to be kept on the induction medium.

\section{Results}

Somatic embryogenesis from cotyledons of nongerminated seeds. 'Caserta Inbred 557311' and 'Seneca Butterbar' were used in initial experiments. Explants on induction medium began to develop a smooth, gelatinous callus at 7 weeks, and embryos were visible on 'Seneca Butterbar' and 'Caserta Inbred 557311' at 10 and 13 weeks, respectively. At 10 weeks, all of the 'Seneca Butterbar' explants were transferred to maturation medium and kept on this medium for 6 weeks, during which time the embryos matured into plantlets (referred to as germinated embryos in Tables 1 and 2). Plantlets that became detached from the explant were individually transferred to hormone-free medium for further development and rooting. Calli with clusters of plantlets also were transferred to hormone-free medium, and plantlets that subsequently became detached were transferred to individual containers.

Sixty-one percent (110) of the 180 'Seneca Butterbar' explants were embryogenic, and 13 of those produced a total of 56 plantlets. Overall, $7 \%$ of the initial explants produced plantlets and regeneration efficiency was calculated as 0.3 plantlets per initial explant. The percentage of embryogenic explants and of explants producing plantlets was based on the total number of explants that had not become contaminated during the initial 5 weeks of the experiment.
To enhance plantlet recovery, cotyledons of 'Caserta Inbred 557311' were divided into six groups and transferred to maturation medium sequentially after explants had been on induction medium for $13,15,16,17,18$, or 19 weeks (Table 1). Explants were kept on maturation medium for 3 to 9 weeks. Individual plantlets or calli with clusters of plantlets were transferred to hormone-free medium as described for 'Seneca Butterbar'. Somatic embryogenesis was $100 \%$ for explants transferred from induction to maturation medium at 13 to 17 weeks. However, most plantlets were recovered when explants were transferred to maturation medium at 15 weeks, with an average of 9.3 plants produced per explant out of $90 \%$ of the explants (Table 1 ). In the statistical analysis, ND-50 values (with a 95\% confidence) obtained by probit analysis showed that the optimal time on induction medium was 15 weeks (Table 1, see note). Data are for explants in Table 1 that had not become contaminated during the first 10 weeks in induction medium.

Plantlets elongated and rooted 12 to 24 days after they were individually placed on hormone-free medium. Fully rooted plantlets that were ready for transplanting to the greenhouse were obtained from cotyledons after $\approx 5$ months in culture. Plantlets were established in soil using the procedure previously described for melons (Gonsalves et al., 1994).

Plants of 'Seneca Butterbar' (14) and 'Caserta Inbred 557311' (18) were selected to produce seeds in the greenhouse. Somatic embryogenesis and plantlet production also were obtained from 'Dixie', 'Jade', and 'President' by using the media described in our report, but data was not taken on efficiency of regeneration. Five, two, and eight plants of 'Dixie', 'Jade', and 'President', respectively, were transferred to a greenhouse. Seeds were obtained from all five cultivars regenerated from nongerminated seed.

Somatic embryogenesis from cotyledons of germinated seeds. 'Seneca Zucchini' explants were divided randomly into five groups (22 to 40 explants) and placed on induction medium. Cotyledons began to form a smooth, gelatinous callus at 7 weeks and were transferred to maturation medium after $11,13,14,15$, or 16 weeks (Table 2). Unlike results obtained for 'Caserta Inbred 557311', the probit analysis (ND-50 value) for 'Seneca Zucchini' showed that the optimal time on induction medium was 13 weeks (Table 2, see note). Individual plantlets or clusters of plantlets were transferred to hormone-free medium as described for 'Seneca Butterbar'. Somatic embryogenesis occurred in nearly all explants regardless of the time of transfer to maturation medium, but plantlet production and recovery was greatest for explants transferred at 13 weeks. An average of 4.5 plants were produced per explant out of $70 \%$ of the explants (Table 2). Data in Table 2 are for explants that did not become contaminated during the first 11 weeks in induction medium. Twenty-two plants were grown in the greenhouse for seed production.

Plant morphology and seed production. Plants that were individually transferred from maturation to hormone-free medium or plantlets that became detached from calli within 3 weeks after the calli had been transferred to hormone-free medium generally developed into normal-looking plants. However, many plantlets that subsequently developed from these calli appeared abnormal. For example, $70 \%$ (35 of 50) of 'Seneca Zucchini' and 68\% (68 of 100) of 'Caserta Inbred 557311' plants recovered had flat striated stems and clusters of leaves. Generally, such plants were dis-

Table 1. Squash somatic embryogenesis and plantlet recovery from cotyledons excised from nongerminated mature seeds of 'Caserta Inbred 557311' following sequential transfer ${ }^{2}$ from induction to maturation medium.

\begin{tabular}{|c|c|c|c|c|c|}
\hline \multirow{2}{*}{$\begin{array}{l}\text { Wks on embryo } \\
\text { induction medium }\end{array}$} & \multirow{2}{*}{$\begin{array}{c}\text { No. } \\
\text { explants }\end{array}$} & \multicolumn{2}{|c|}{ \% Explants producing } & \multirow{2}{*}{$\begin{array}{c}\text { Total no. } \\
\text { plants }\end{array}$} & \multirow{2}{*}{$\begin{array}{c}\text { Avg no. } \\
\text { plants/explant }\end{array}$} \\
\hline & & Embryos & Germinated embryos & & \\
\hline$\overline{13}$ & 6 & 100 & 100 & 6 & 1.0 \\
\hline 15 & 10 & 100 & 90 & 93 & 9.3 \\
\hline 16 & 13 & 100 & 77 & 22 & 1.7 \\
\hline 17 & 20 & 100 & 50 & 22 & 1.1 \\
\hline 18 & 24 & 50 & 13 & 7 & 0.3 \\
\hline 19 & 21 & 67 & 19 & 6 & 0.3 \\
\hline
\end{tabular}

${ }^{2}$ The probit line for 'Caserta Inbred 557311' had a slope of $b=24.95$ and an intercept of -24.25 . Therefore, $Y_{t}=-24.25+24.95 \log \left(X_{t}\right)$. The ND-50 for this line was 14.86 and the ND95 was 17.30 . The $95 \%$ confidence interval for the ND-50 was between 14.68 and 15.03. This indicates that the median of the distribution is at 14.86 or 15 weeks. Data show that optimal production of plants was at 15 weeks on a confidence level of $95 \%$.

Table 2. Squash somatic embryogenesis and plantlet recovery from cotyledons excised from germinated seeds of 'Seneca Zucchini' following sequential transfer ${ }^{2}$ from induction to maturation medium.

\begin{tabular}{|c|c|c|c|c|c|}
\hline \multirow{2}{*}{$\begin{array}{l}\text { Wks on embryo } \\
\text { induction medium }\end{array}$} & \multirow{2}{*}{$\begin{array}{c}\text { No. } \\
\text { explants }\end{array}$} & \multicolumn{2}{|c|}{ \% Explants producing } & \multirow{2}{*}{$\begin{array}{c}\text { Total no. } \\
\text { plants }\end{array}$} & \multirow{2}{*}{$\begin{array}{c}\text { Avg no. } \\
\text { plants/explant }\end{array}$} \\
\hline & & Embryos & Germinated embryos & & \\
\hline$\overline{11}$ & 22 & 100 & 32 & 19 & 0.9 \\
\hline 13 & 30 & 100 & 70 & 134 & 4.5 \\
\hline 14 & 24 & 100 & 29 & 17 & 0.7 \\
\hline 15 & 40 & 70 & 8 & 5 & 0.1 \\
\hline 16 & 22 & 100 & 68 & 2 & 0.1 \\
\hline
\end{tabular}

${ }^{2}$ The probit line for 'Seneca Zucchini' was $Y_{t}=-26.23+28.87 \log \left(X_{t}\right)$ for which an ND-50 = 12.07 was found within the $95 \%$ confidence interval of 11.91 and 12.21. Data show that optimal production of plants were at 13 weeks on a confidence interval of $95 \%$. 
carded; however, we were able to root in vitro cuttings of nondistorted side shoots, which sometimes existed on plants with abnormal leaves and stems. When planted in soil, distorted plants grew normal leaves and stems; however, only healthy, normal plants were selected for seed production in the greenhouse.

\section{Discussion}

Using somatic embryogenesis of cotyledon explants, we regenerated squash plants that produced fruit and seeds from six summer squash cultivars. Our work expands on that of Chee (1992), who regenerated 'YC 60' plants from cotyledons of nongerminated seeds. Because our protocol was successfully applied to six cultivars, it likely is applicable to other squash genotypes. We also show that abundant embryo production can occur from cotyledons excised from germinated or nongerminated seeds. To our knowledge, our report is the first to report squash regeneration using cotyledon explants from germinated seeds.

Our best rates of somatic embryogenesis for cotyledons from nongerminated seed $(100 \%$ for 'Caserta Inbred 557311' and 61\% for 'Seneca Butterbar') were higher than those reported by Chee (1992), who obtained embryogenesis rates of $5 \%$ and $28 \%$ for ' $Y C$ 60' cotyledons with and without the embryonic axis, respectively. We also showed that all cotyledons from germinated 'Seneca Zucchini' seeds became embryogenic. There may be several reasons for our higher rates. First, our media and culture conditions differed from those of Chee. For example, our embryo induction medium was the same as that described for cotyledon explants by Chee (1992), but our embryo maturation medium was the same as that described for shoot apex explants
(Chee, 1991). Second, we maintained explants in induction medium over longer periods than the 10 weeks reported by Chee (1992). Probit statistical analyses confirmed $95 \%$ confidence intervals for the 13- to 15-week exposure to induction medium to produce optimal somatic embryogenesis and recovery of plants. Third, others (Debeaujon and Branchard, 1993) have shown that genotypes often respond unequally in tissue culture. Last, the process of deriving somatic embryos from plant tissue is complex and not entirely predictable (Zimmerman, 1993).

Contamination, fungal and bacterial, can be a major obstacle to successful squash regeneration. Twelve prior experiments (not reported here)were terminated due to excessive contamination rates. Most of the losses occurred during the first 5 to 11 weeks on induction medium. In 'Caserta Inbred 557311', $54 \%$ of the experiment became contaminated during the first 11 weeks. We believe that careful attention to seed selection and sterilization procedures and the inclusion of carbenicillin $\left(500 \mathrm{mg} \cdot \mathrm{liter}^{-1}\right)$ in all media are helpful in reducing contamination.

We conclude that cotyledons are an efficient and dependable explant source for development of somatic squash embryos. Moreover, our procedure should be applicable for other squash cultivars. The cultivars described, whether the green zucchini or yellow summer squash, are consumed in the United States and in one or more countries in Europe, the Middle and Far East, Central and South America, and Mexico.

\section{Literature Cited}

Beachy, R.N., S. Loesch-Fries, and N.E. Tumer. 1990. Coat protein-mediated resistance against virus infection. Annu. Rev. Phytopathol. 28:451474.
Chee, P.P. 1991. Somatic embryogenesis and plant regeneration of squash Cucurbita pepo L. YC 60. Plant Cell Rpt. 9:620-622.

Chee, P.P. 1992. Initiation and maturation of somatic embryos of squash (Cucurbito [sic] pepo). HortScience 27(1):59-60.

Debeaujon, I. and M. Branchard. 1993. Somatic embryogenesis in Cacurbitaceae. Plant Cell Tiss. Organ Cult. 34:91-100.

Fitch, M.M.M., R.M. Manshardt, D. Gonsalves, J.L. Slightom, and J.C. Sanford. 1992. Virus resistant papaya plants derived from tissues bombarded with the coat protein gene of papaya ringspot virus. Bio/Technology 10:14661472.

Food and Agriculture Organization of the United Nations. 1993. Yearbook. Production, vol. 46. Food and Agr. Organization, Rome.

Gonsalves, C., B. Xue, M. Yepes, M. Fuchs, K Ling, S. Namba, P. Chee, J.L. Slightom, and D. Gonsalves. 1994. Transferring cucumber mosaic virus-white leaf strain coat protein gene into Cucumis melo L. and evaluating transgenic plants for protection against infections. J. Amer. Soc. Hort. Sci. 119:345-355.

Jelaska, S. 1972. Embryoid formation by fragments of cotyledons and hypocotyls in Cucurbita pepo. Planta 103:278-280.

Munger, H.M. 1993. Breeding for viral disease resistance in cucurbits, p.44-60. In: M.M. Kyle (ed.). Resistance to viral diseases of vegetables. Timber Press, Portland, Ore.

Murashige, T. and F. Skoog. 1962. A revised medium for rapid growth and bioassays with tobacco tissue cultures. Physiol. Plant. 15:473497.

Sanford, J.C. and S.A. Johnston. 1985. The concept of parasite-derived resistance-Deriving resistance genes from the parasite's own genome. J. Theor. Biol. 113:395-405.

Schroder, C.A. 1968. Adventive embryogenesis in fruit pericarp tissue in vitro. Bot. Gaz. 129:374376.

Zimmerman, J.L. 1993. Somatic embryogenesis: A model for early development in higher plants. Plant Cell 5:1411-1423. 